\title{
THE EFFECT OF FREQUENCY EXCITATION AND CAVITY SHAPE CHANGES ON THE VORTEX RING FORMATION OF A SYNTHETIC JET ACTUATOR
}

\author{
Dewi Larasati ${ }^{1 *}$, Harinaldi $^{1}$, Ramon Trisno ${ }^{1}$ \\ ${ }^{1}$ Department of Mechanical Engineering, Faculty of Engineering Universitas Indonesia, Kampus Baru \\ Depok, Indonesia 16242
}

(Received: November 2016 / Revised: June 2017 / Accepted: December 2017)

\begin{abstract}
This paper provides an explanation of the effects of cavity shape and frequency excitation on the vortex formation of a synthetic jet. In order to obtain comprehensive results, this study used both computational and experimental methods. The experimental method was prepared by applying a hotwire probe on the center point of the synthetic jet orifice to obtain the Ux (average airflow velocity from membrane movement) in a low voltage signal. The data were then transferred to an analog data converter within a record speed of 10,000 data/s. The following cavity shapes were studied: half-sphere, tubes, and conical. The studied orifice diameters were $3 \mathrm{~mm}, 5 \mathrm{~mm}$, and $8 \mathrm{~mm}$. The simulation began by utilizing the flow rate data from the experiment, which can be put in the Computational Fluid Dynamics (CFD) simulation boundary condition. From the visual data of the flow contour from the CFD simulation it is possible to determine the vortex ring formation quality from the Synthetic Jet Actuator (SJA). Based on this result, vortex ring formation occurs at the B3, T3, T5, K3, and K5 configurations of the SJA. The synthetic jet cavity with an $8 \mathrm{~mm}$ orifice diameter did not produce the vortex ring.
\end{abstract}

Keywords: Active flow control; Ahmed body; Airflow separation; Drag force; Vortex ring

\section{INTRODUCTION}

Today, global warming is a serious problem that needs to be considered. According to the International Energy Agency (IEA) World Energy Outlook 2007, greenhouse gas emissions will increase up to $57 \%$ by 2030 (IEA, 2007). In 2001, the Intergovernmental Group of Experts on the Evolution on Climate Evolution (GIEC) declared that human activity is the primary cause of the temperature increase and the abundance of greenhouse gas emissions in the 20th century (GIEC, 2001). One of the human activities that have the most significant impact on climate change is the increasing number of private transportation sales. Many aerodynamic researchers have conducted experiments and simulations to study transportation technology in order to reduce world fuel consumption. Previous studies used a simple model that has a relevant airflow feature of a real vehicle body (Ahmed, 1984; Hintenberger et al., 2004; Fares, 2006; Minguez, 2008; Uruba, 2009; Kourta \& Gillieron, 2009). Other studies have investigated passive flow control applied to a transportation prototype conducted in a wind tunnel (Gak-ElHak, 1996; Hucho, 1998); they concluded that passive flow control has a limited effect on aerodynamic drag reduction because the initial flow condition is turbulent and, in addition to

\footnotetext{
*Corresponding author's: dewi.larasati.mech.eng.ui.13@gmail.com, Tel.+62-21-7270032, Fax.+62-21-7270033 Permalink/DOI: https://doi.org/10.14716/ijtech.v8i7.730
} 
the surface friction, the aerodynamic drag reduction is only about $10 \%$ (Kourta \& Gillieron, 2009). The role of flow control is to reduce the overall aerodynamic drag. Based on previous research, the flow separation between the front and rear areas of a vehicle causes a drastic pressure difference, which is the main cause of overall drag (Hucho, 2002). More recent solutions for airflow control use active controls. For an automotive engineer, the potential advantage of applying active flow control is that it does not require changing the shape of the vehicle's surface as is typically done with passive airflow control. An active control actuator that can produce continuous blowing and suction of airflow can modify the flow separation, resulting in a 20\% drag reduction (Roumeas, 2009). Bruneau et al. (2011) conducted a relevant experiment to investigate the effect of the actuator position variations on a vehicle's body. They concluded that the active control device, which was located in the rear area of an Ahmed body model, resulted in a 13\% drag. The numerical study conducted by Roumeas (2009) concluded that the synthetic jet active flow control applied on the top of an Ahmed model reduced overall drag by $13 \%$. Since the research study discussed in the present paper focuses on the effect of synthetic jet installation on aerodynamic drag reduction of a public transportation, it is necessary to conduct an in-depth examination of how to increase the performance of a synthetic jet in order to reduce aerodynamic drag.

Thus, the present study focuses on the necessity of identifying the characteristics of different types of cavities and different orifice diameters of a Synthetic Jet Actuator (SJA); it also aims to determine the influence of frequency excitation on the performance of an SJA as an active control device for reducing aerodynamic drag. The research results will explain how cavity shape, orifice diameter variations, and frequency excitation of an SJA affect vortex ring formation.

\section{METHODS}

In order to achieve maximum drag reduction on a Ahmed body model, we need to know the characteristics and parameters that can affect an SJA's performance. By varying the cavity shape and the orifice diameter of the SJA through experiments and a Computational Fluid Dynamics (CFD) simulation, the performance of each synthetic jet can be compared. The cavity shapes that will be studied are half-sphere, tube, and conical, and the orifice diameter variations of each of these cavities are $3 \mathrm{~mm}, 5 \mathrm{~mm}$, and $8 \mathrm{~mm}$. Figure 1 shows the experimental setup of the SJA performance test, and Figure 2 shows the shapes and diameters of the cavities. The component consists of the synthetic jet cavity, which is installed inside the Ahmed body, a piezoelectric membrane, and the function generator, which can set the membrane frequency. In the experiments, a sinusoidal wave was used as the signal. The piezoelectric membrane movement makes the air inside the synthetic jet encounter a blowing and suction process. The air velocity that forms through the orifice was measured using a 55P14 Gold Plate hot wire probe. This hot wire p-type probe has a single wire, with a wire diameter $d_{w}=5 \mu \mathrm{m}$ and a length of $1.2 \mathrm{~mm}$; it was installed inside the SJA. The distance between the SJA and the hot wire probe is about $\pm 0.5 \mathrm{~mm}$ above the SJA orifice. By connecting the hot wire probe in this way, its movement along the $\mathrm{x}$-axis will not crash into the synthetic jet cavity. After the component installation is completed, the data recording process begins. Before collecting the data, it is necessary to calibrate the hot wire probe using a calibration unit and King's Law, which is suitable for calibrating the recorded speed. The range of calibration performance must be 0:02$30 \mathrm{~m} / \mathrm{s}$. The hot wire probe is connected to the Data Logger in order to record the low voltage data. Then, the weak voltage data is entered into the Data Acquisition Board. This tool converts analog data into digital data. Furthermore, the Data Acquisition Board is connected to a computer, which is also connected to the Data Logger, which serves to control the speed of the data recording. 


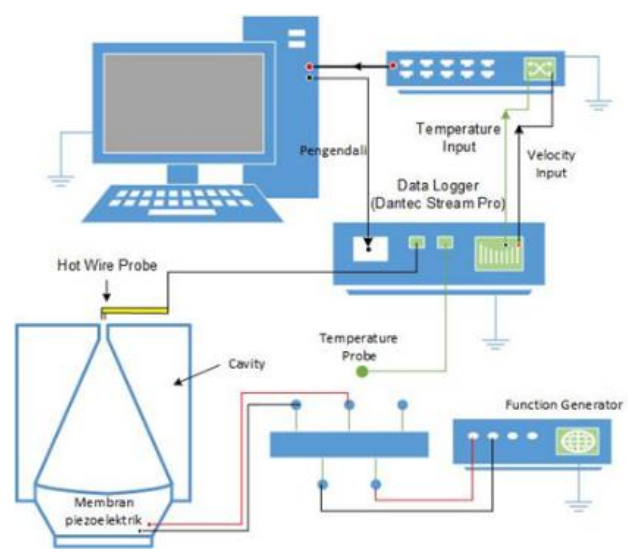

Figure 1 Schematic of the synthetic jet performance test
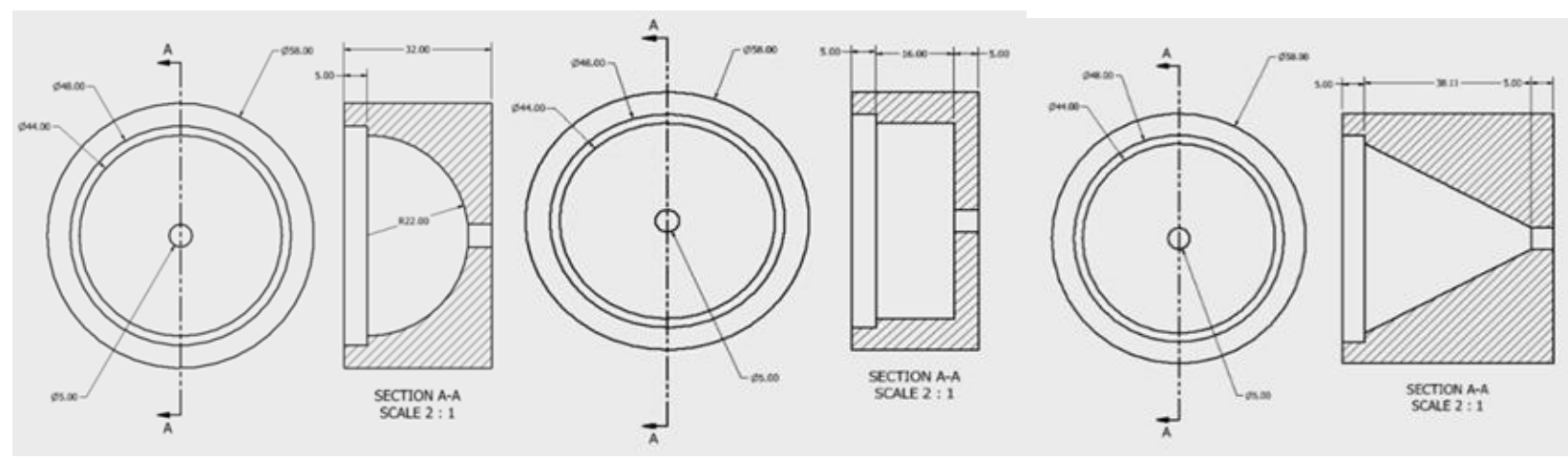

Figure 2 The shapes and diameters of the cavities: half-sphere (B3, B5, B8), tube (T3, T5, T8), and conical $(\mathrm{K} 3, \mathrm{~K} 5, \mathrm{~K} 8)$

The measurement uncertainty of the velocity data is about $2.5 \%$. The radial velocity across the synthetic jet is measured by the hot wire probe, which is placed close to the orifice area, and the probe mounted to the traverse system (vise). The displacement distance is measured using a dial indicator with $0.01 \mathrm{~mm}$ accuracy. The velocity data acquisition procedure is done under two conditions. First, the velocity measurement is used to determine the frequency that can produce the maximum amount of outflow for the synthetic jet. Second, by varying the sinusoidal frequency from the function generator, the maximum velocity and allowable amount of data are obtained. The frequency variation ranges from $20 \mathrm{~Hz}$ to $200 \mathrm{~Hz}$. The amount of data is 60,000 when the data recording speed is 30,000 data/s. Then, the jet velocity measurement is taken at the $X / D, Y / D$ coordinates to obtain the variations. The jet velocity is only measured at the halfpoint region, since the location of the synthetic jet formation is considered to be symmetrical. The value of $X / D$ ranges from 0 to 4 , with interval increments of 0.25 , and the value of $Y / D$ ranges from 0 to10, with interval increments of 1.0. The data record speed is 10,000 data/s; hence, 6 seconds are needed to obtain 60,000 data in one-point measurement. For the computational simulation, the investigation used a commercial CFD known as Fluent, which is part of ANSYS Fluent CFD software. The purpose of this simulation was to obtain an overview of the initial synthetic jet performance. The data obtained from the simulation was compared to the experimental data and the results from the visual analysis of the vortex ring formation from the SJA. The essential parameters were the same in both the experiment and the simulation. 


\section{RESULTS AND DISCUSSION}

\subsection{Frequency Testing and Mesh Independencies}

The first stage of the experiment is to determine the frequency that can produce the maximum SJA flow rate produced; then, the data are used as reference in the next stage. The synthetic jet performance test was done by varying the frequency of the wave function generator; for this purpose, a sinusoidal wave was used. The graph in Figure 3 shows the synthetic jet performance for each cavity shape and orifice diameter using different test frequencies. The maximum frequency selection was based on the maximum velocities from the synthetic jet orifice. The maximum jet velocity was produced by the conical shaped cavity orifice with a diameter of $3 \mathrm{~mm}$ when the frequency range is $110 \mathrm{~Hz}-130 \mathrm{~Hz}$ and the maximum jet velocity average is $9.92 \mathrm{~m} / \mathrm{s}$. The frequency that can produce the highest jet velocity was used as the simulation set-up reference. The maximum frequency is used in the User Defined Function for computational work with Fluent. The computational method was conducted using CFD software, the meshing was generated by Gambit software, and the section test was conducted using Fluent. The purpose of the meshing simulation is to produce the most accurate iteration in CFD. Each type of cavity has a different shape and a different meshing size. The cavity shape and meshing size were then adapted to the experiments. The CFD simulation results illustrate the speed of the jet at the X/D $=0$ and $Y / D=0$ positions with the data record rate of $0.0001 / \mathrm{s}$. The uncertainty (uncertainty of quantitative measurements) is not reported as a single value, but it showed a range of the estimated actual value. The measurement results may vary, and this deviation is due to many factors, including tool error, measurement methods, and environmental conditions. Uncertainty aims to determine the extent of accuracy in obtaining the amount of data. In the experiments, for each measurement point, as many as 60,000 data were collected, which took 6 seconds (10,000 data/s).

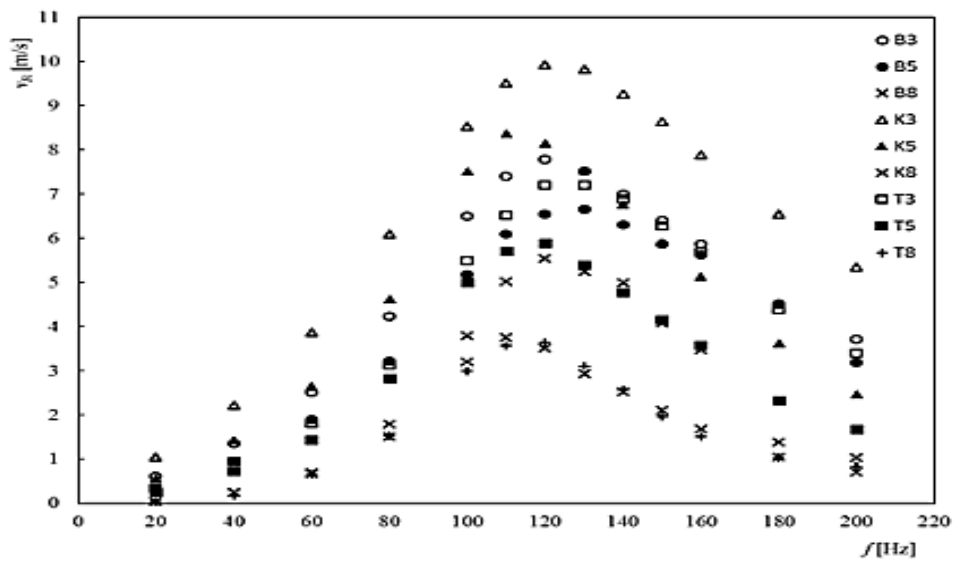

Figure 3 The synthetic jet actuator test results by sinusoidal wave types

In the simulation, as many as 10,000 data/s were also obtained. Thus, the results have a 95\% confidence interval (CI) level. The formula for uncertainty is shown in Equation 1; in the present work, a 95\% CI level benchmark was applied.

$$
U_{x} \propto \sigma_{x} \rightarrow U_{x} \approx K \text { (convidence limit) }
$$

The information presented in Figures 4-6 explains the results of the uncertainty calculation in each type of cavity, which is based on the number of samplings at 10,000 data/s. The processed data were obtained at the $Y / D=0$ and $X / D=0$ conditions. The point $(0,0)$ is $0.5 \mathrm{~mm}$ above the orifice hole in order to prevent the movement of the probe from coming into contact with the surface of the SJA. Based on the data obtained from the experiments and the CFD simulations, 
the B3 cavity has a greater uncertainty value than the other types of the cavity. The uncertainty value of the experimental method is $1.61 \%$; for the CFD simulation results, that value is $1.28 \%$. While the smallest uncertainty value occurs in the B8 cavities, the respective uncertainty of its value is $0.98 \%$ for the experimental method and $1.06 \%$ for the CFD simulation method. The purpose is to obtain $95 \%$ CI for the data, so the value of the uncertainty needs to be considered further; it should not be greater than $5 \%$.

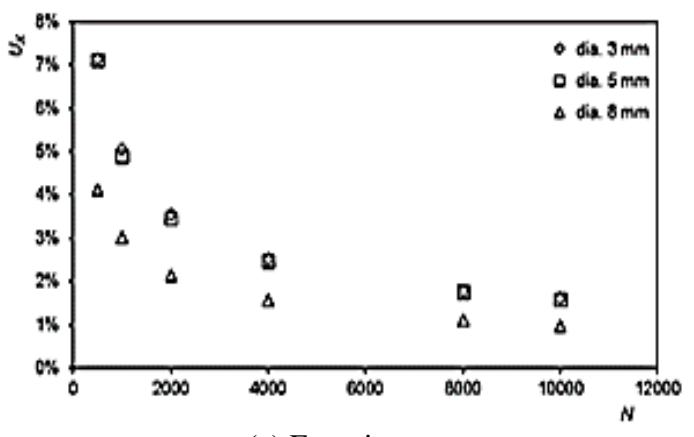

(a) Experiment

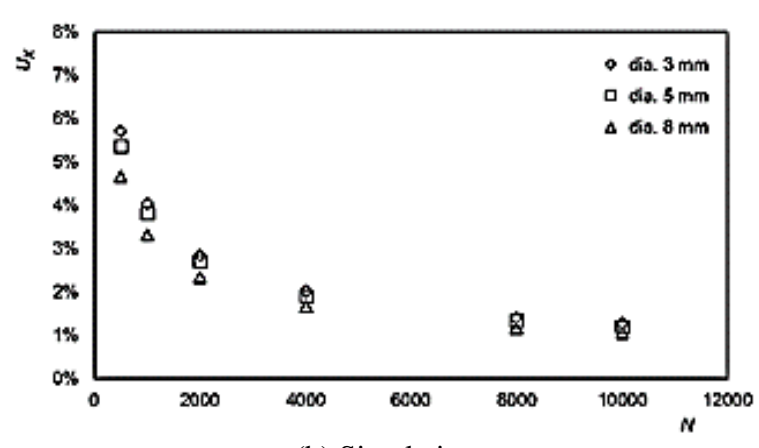

(b) Simulation

Figure 4 The uncertainty of the half-sphere cavity synthetic jet

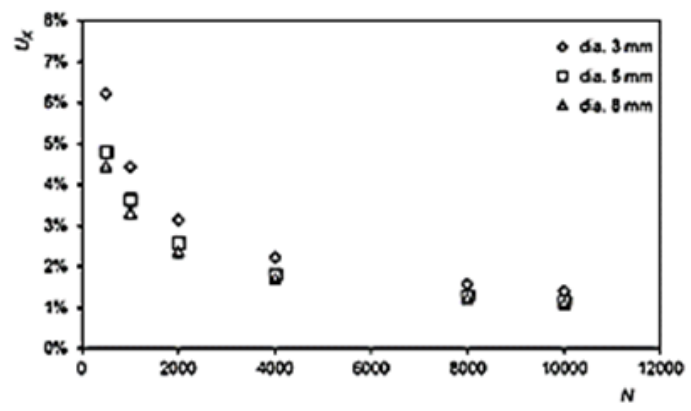

(a) Experiment

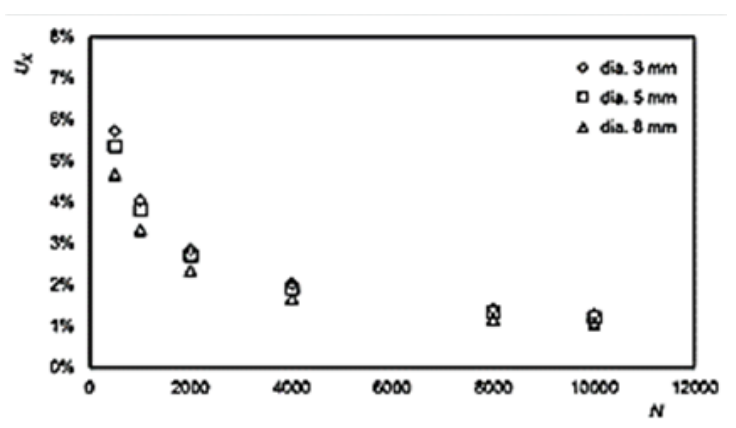

(b) Simulation

Figure 5 The uncertainty of the conical cavity synthetic jet

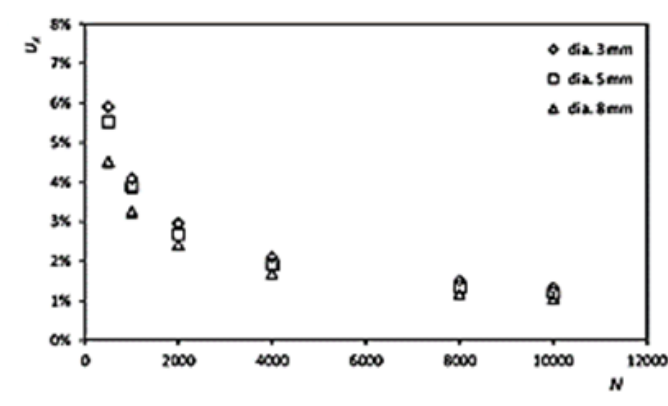

(a) Experiment

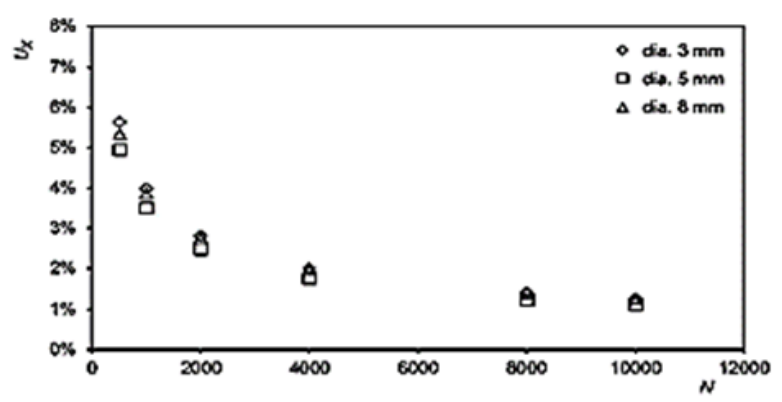

(b) Simulation

Figure 6 The uncertainty of the tube shaped synthetic jet

\subsection{Vortex Ring Determination}

The characteristics of the flow velocity of the SJA were obtained from the velocity located in the center line, which is the upper control limit (UCL). It is assumed that the highest velocity profile is at the exit orifice. The spatial velocity profile can show the standard deviation of the highest velocity value formed; for some of the speed scales, the average flow rate occurs through the expulsion stroke (Utturkar, 2002), as seen in Equation 2. 


$$
U=\frac{1}{\frac{T}{2}} \frac{1}{A n_{A n}} \iint_{0}^{\frac{T}{2}} U(t, A n) d t d_{A n}
$$

where $U$ is the velocity at the average axial phase, $T$ is the period of excitation, and $A_{n}$ is the cross-sectional area of the exit orifice. The average velocity can be used to determine the Reynolds number. The stroke length, $L_{o} / D$, is important to consider when evaluating the length scale of the synthetic jet stream (Smith \& Glezer, 1998, Smith \& Swift, 2001; Glezer, 1998), as shown in Equation 3.

$$
L_{o}=\int_{0}^{\frac{T}{2}} U_{A v e}(t) d t
$$

$U_{\text {ave }}$ is the average jet flow velocity spatially. The stroke length is the distance the fluid travels during the process of pushing the fluid from the cycle. Excitation frequency can be nondimensional, as Stokes numbers, $S$, as shown in Equation 4.

$$
S=\sqrt{\frac{2 \pi f D^{2}}{v}}
$$

The non-dimensional parameter can determine the operating conditions of the SJA, which affects its ability to transfer linear momentum. Equation 5 explains that the expulsion stroke vortex that reaches the exit is defined as vortex ring formation (Holman, 2005).

$$
\frac{R e_{u}}{s^{2}}>C
$$

where $C$ is a constant equal to 0.16 for the axis symmetric and 1 for the rectangular nozzles. According to Utturkar (2002), the condition of the occurrence of the vortex ring formation is $R e_{U} / S_{2}>1$. According to Smith and Swift (2001), the ring vortex can occur if:

$$
\frac{L_{o}}{D}=S t>6
$$

Table 1 The vortex ring calculation results

\begin{tabular}{|c|c|c|}
\hline $\begin{array}{c}\text { Cavity } \\
\text { type }\end{array}$ & Experiment & Simulation \\
\hline B3 & $\sqrt{ }$ & $\sqrt{ }$ \\
\hline B5 & $\mathrm{X}$ & $\mathrm{X}$ \\
\hline B8 & $\mathrm{X}$ & $\mathrm{X}$ \\
\hline T3 & $\sqrt{ }$ & $\sqrt{ }$ \\
\hline T5 & $\sqrt{ }$ & $\sqrt{ }$ \\
\hline T8 & $\mathrm{X}$ & $\mathrm{X}$ \\
\hline $\mathrm{K} 3$ & $\sqrt{ }$ & $\sqrt{ }$ \\
\hline $\mathrm{K} 5$ & $\sqrt{ }$ & $\sqrt{ }$ \\
\hline $\mathrm{K} 8$ & $\mathrm{X}$ & $\mathrm{X}$ \\
\hline
\end{tabular}

Table 2 Comparison of vortex ring formation

\begin{tabular}{|c|c|c|c|}
\hline Cavity & Reu & Reu/s $^{2}$ & $\mathrm{~L}_{o} / \mathrm{D}$ \\
\hline B3 & 1201.32 & 2.768 & 16.248 \\
\hline B5 & 1092.08 & 0.836 & 5.25 \\
\hline B8 & 1367.35 & 0.443 & 2.782 \\
\hline T3 & 1837.03 & 3.92 & 12.31 \\
\hline T5 & 2469.24 & 2.055 & 6.453 \\
\hline T8 & 2462.2 & 0.801 & 2.516 \\
\hline K3 & 1418.34 & 3.05 & 19.20 \\
\hline K5 & 1711.13 & 1.44 & 9.09 \\
\hline K8 & 1091.83 & 0.36 & 2.26 \\
\hline
\end{tabular}

Table 1 shows the results of the calculations for Equations 2-6. Table 2 shows the comparisons of vortex ring formation for each type of SJA being investigated in this work. Based on the calculations, the ring vortex data from the experiments can be compared to the CFD simulations results. Figure 7, Figure 8, and Figure 9 show the vortex ring formation process in the halfsphere synthetic jet cavity with orifice diameters of $3 \mathrm{~mm}, 5 \mathrm{~mm}$, and $8 \mathrm{~mm}$, which was 
processed using Fluent software. Figure 7 shows the contour of the flow velocities caused by the movement of the B3 synthetic jet membrane. When the membrane oscillates at $t / T=1 / 8$, it starts to blow air from the jet out from the orifice, so the presence of air flowing out through the orifice is visible. Then, at $t / T=1 / 4$ the contour of the flow velocities begins to show the formation of the vortex rings. The condition of $t / T=1 / 4$ is the peak stroke expulsion that is formed by the movement of the membrane. The membrane began to start the suction process after reaching the position of $t / T=3 / 8$, then the vortex ring can be seen more clearly. After reaching the position of $t / T=1 / 2$, the vortex ring starts to break away and move away from the end of the orifice.

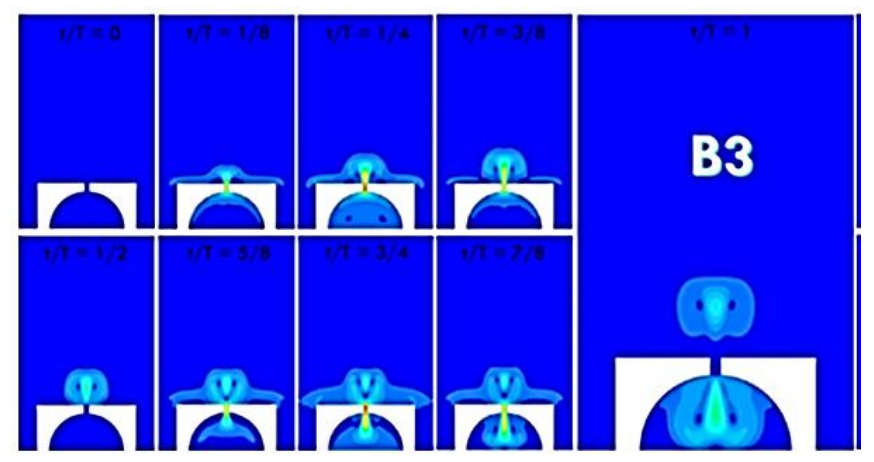

Figure 7 Vortex ring formation in the half-sphere cavity (diameter $3 \mathrm{~mm}$ )

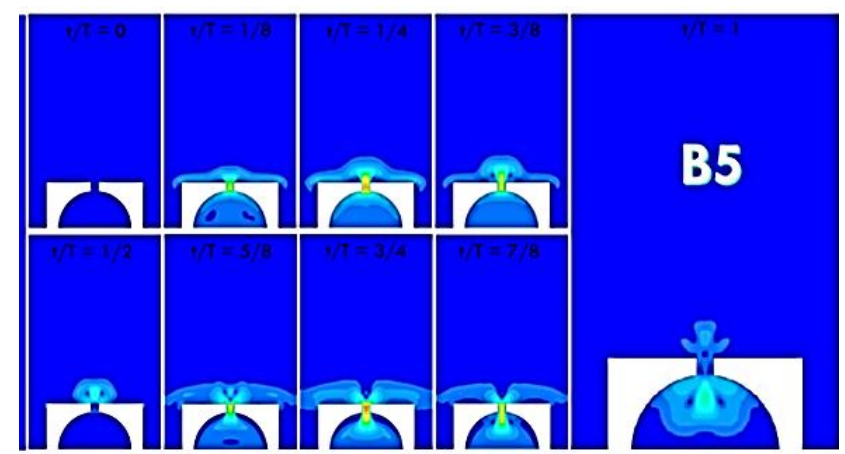

Figure 8 Vortex ring formation on half-sphere cavity (diameter $5 \mathrm{~mm}$ )

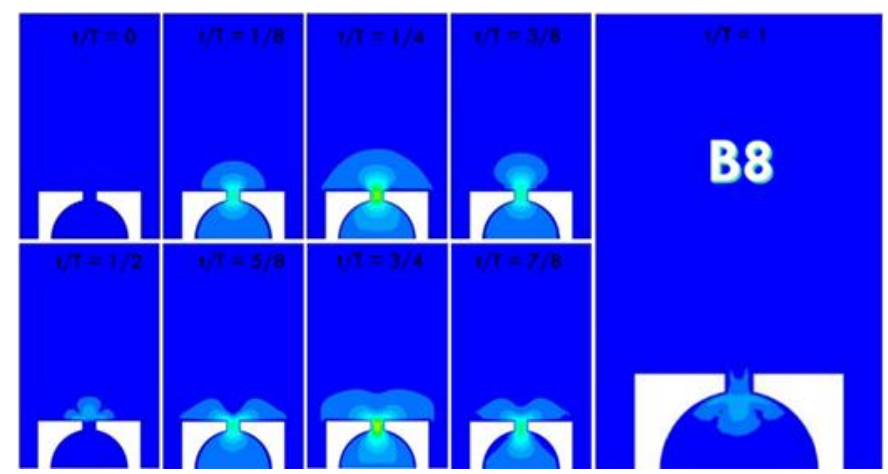

Figure 9 Vortex ring formation in the half-sphere cavity (diameter $8 \mathrm{~mm}$ )

The suction movement continued to stage $t / T=5 / 8$; in this condition, the air in the vortex ring goes back inside the cavity. This process can affect the shape of a vortex ring that has been formed by the blowing process. Vortex ring that has been formed remains stable and is more intense in the $t / T=3 / 4$ position. Then, in the $t / T=7 / 8$ position, the membrane starts to oscillate 
and the SJA starts to blow. In this section, the vortex ring has been formed and it is ready to break away due to the formation of a new vortex ring. At the $t / T=1$ position, the vortex ring seems to have been released from the end of the orifice. Figure 8 shows the contours of the jet velocity produced by the B5 synthetic jet cavity. As seen, the vortex ring begins to form at the $t / T=1 / 4$ position. Then, in the $t / T=3 / 5$ position the vortex ring begins to move and it is separated from the end of the orifice. This is more noticeable at the $t / T=1 / 2$ position, when the vortex ring will leave the end of the orifice. However, when the membrane moves down to the $t / T=5 / 8$ position, the synthetic jet membrane starts the suction process, so most of the jet air around the orifice begins to go inside the cavity, and the vortex ring that was formed is impacted by the suction process, as shown in the $t / T=3 / 4$ position. Consequently, the vortex rings start to separate at the $t / T=7 / 8$ position, and the vortex ring fails to form, as shown in the $t / T=1$ position. As seen in Figure 9, vortex ring formation does not occur in B8 cavity since after the end of blowing process at $\mathrm{t} / \mathrm{T}=3 / 8$, the air spreads through the orifice surface and it continues to the suction process.

\subsection{Effects of Frequency Excitation on Synthetic Jet Formation}

In the vortex ring formation, frequency excitation often affects the magnitude of the jet velocity from the SJA. This phenomenon has an impact on the SJA's ability to form a vortex ring. From Figure 1 it can be seen that the experimental conditions demonstrated that frequency excitation effects the vortex ring formation.

Figure 8 shows the results of the calculations using the vortex ring Equation 3 proposed by Smith and Swift (2001) to obtain $L o / D$ at different frequencies. The results of this calculation show the vortex ring formation differences for each type of cavity. The red line on the $L o / D=6$ separates the graph areas where a vortex ring is formed from the areas where a vortex ring is not formed. The region under the red line includes vortex ring formation data from the SJA with a $3 \mathrm{~mm}$ cavity orifice diameter. Due to high-frequency excitation, the amount of vortex ring formation begins to decrease; thus, it can be said that the higher excitation frequency, the lower the number of ring vortices that will be produced. For the cavity with a $5 \mathrm{~mm}$ orifice diameter, only a portion of the frequency can form a vortex ring. At high frequency excitation, most of the SJAs can no longer form a vortex ring. Vortex ring formation occurs at a certain frequency that can produce the maximum jet velocity. The cavity with an $8 \mathrm{~mm}$ orifice diameter cannot form a vortex ring even though it was tested using different frequencies and wave types.

Only the B8 cavity could be expected to form a vortex ring at a certain frequency that can produce the maximum jet speed because, in these conditions, the value of $L o / D$ is close to 6 , which is a value required by the Smith and Swift (2001) equation.

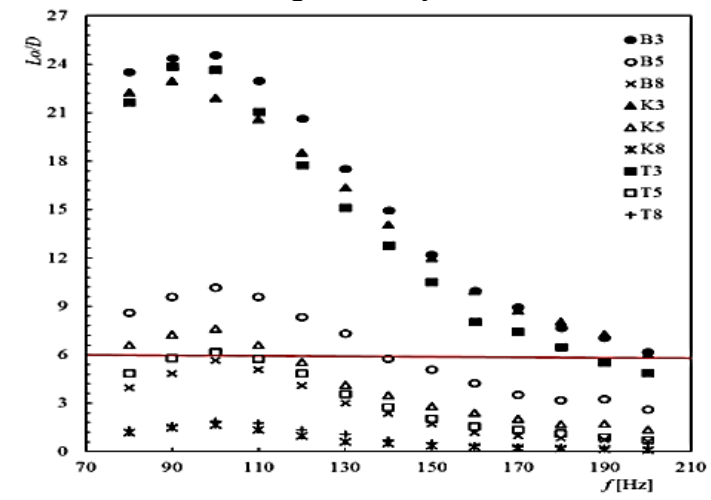

(a)

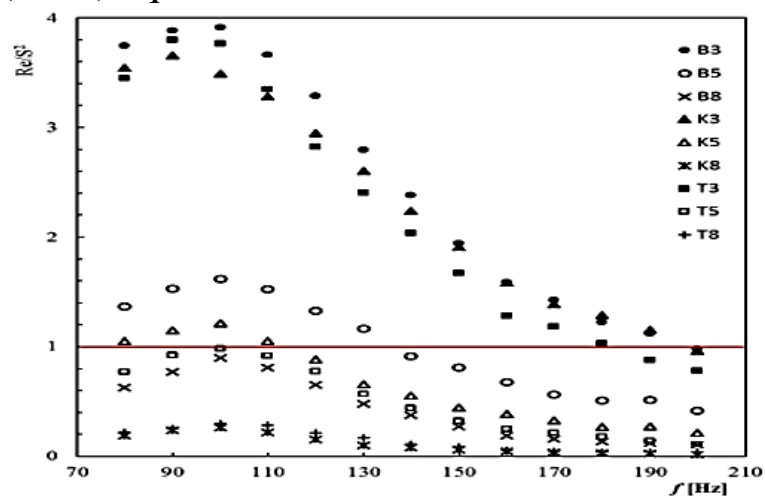

(b)

Figure 10 Vortex ring formation criteria using calculation: (a) Swift; and (b) Smith 


\section{CONCLUSION}

Based on the findings from this research, it can be concluded that $10,000 / \mathrm{s}$ is the maximum jet speed generated by the SJA in the frequency range of $110 \mathrm{~Hz}-130 \mathrm{~Hz}$ with an uncertainty of $2 \%$ and a data amount of 10,000 . The highest velocity jet is produced by $\mathrm{K} 3$ (conical cavity) with an orifice diameter of $3 \mathrm{~mm}$. The average jet velocity generated reached $9.98 \mathrm{~m} / \mathrm{s}$. The vortex ring formation can be determined by the experiments and the CFD simulation method. Based on the experimental and simulation data, it can be concluded that the vortex ring formation equation calculation results were the same for both methods. Vortex ring formation can occur in B3, T3, T5, K3, and $\mathrm{K} 5$ synthetic jet cavities. A vortex ring is not formed on any type of cavity with an orifice diameter of $8 \mathrm{~mm}$. In addition, determination of the occurrence of vortex ring formation can also be evaluated from the equation proposed by Utturkar (2002). The condition of $\operatorname{Re} / S^{2}>1$ is indicative for certain frequency excitations to produce a vortex ring. Thus, it can be said that the results from the simulation and experiments conducted in the present study provide some evidence to support the theory of vortex ring formation mentioned by some previous researchers.

\section{REFERENCES}

Ahmed, S., Ramm, G., Faltin, G., 1984. Some Salient Features of the Time-averaged Ground Vehicle Wake. SAE Technical Paper 840300, 1984, https://doi.org/10.4271/840300

Bruneau, C.-H., Creuse, E., Depeyras, D., Gillieron, P., Mortazavi, I., 2011. Active Procedures to Control the Flow Past the Ahmed Body with a $25^{\circ}$ Rear Window. International Journal Aerodynamics, Volume 1(3/4), pp. 299-317

Conan, B., Anthoine, J., Planquart, P., 2011. Experimental Aerodynamic Study of a Car-type Bluff Body. Experiments in Fluids, Volume 50(5), pp. 1273-1284

Fares, E., 2006. Unsteady Flow Simulation of the Ahmed Reference Body using a Lattice Boltzmann Approach. Computers and Fluids, Volume 35(8-9), pp. 940-950

Gak-El-Hak, M., 1996. Modern Development in Flow Control. Applied Mechanics Reviews, Volume 49(7), pp. 365-379

Glezer, A., 1998. The Formation of Vortex Rings. Physics of Fluids, Volume 31(12), pp. 35323542

Hintenberger C., García-Villalba, M., Rodi, W., 2004. Large Eddy Simulation of Flow around the Ahmed Body. The Aerodynamics of Heavy Vechicles: Truck, Buses, and Trains, Volume 19, pp. 77-87

Holman, R., Utturkar, Y., Mittal, R., Smith, B.L., Cattafesta, L., 2005. Formation Criterion for Synthetic Jets. AIAA Journal, Volume 43(10), pp. 2110-2116

Hucho W.H., 1998. Aerodynamics of Road Vehicle. Annual Review of Fluid Mechanics, Volume 25, pp. 285-537

Hucho, W.H., 2002. Aerodynamik der stumpfer K'"orper - Physikalische Grundlagen und Anwendung in der Praxis (Aerodynamics of Dull K"Orpers - Physical Principles and Application in Practice)

Intergovernmental Group of Experts, 2001. Les Elements Scientifique, 3èmerapport èvaluation 2001 (Scientific Elements, Third Assessment Report 2001). s.1., Available online at http:/ www.grida.no/climate/ippcc_tar

International Energy Agency World Energy Outlook, 2007. Executive Summary, China and India Insights, International Energy Agency IEA. s.1., ISBN: 978-92-64-02730-5

Kourta, A., Gillieron, P., 2009. Impact of the Automotive Aerodynamic Control on the Economic Issues. Journal of Applied Fluid Mechanics, Volume 2(2), pp. 69-75 
Minguez M., Pasquetti, R., Serre, E., 2008. High-order Large Eddy Simulation of Flow over the "Ahmed Body" Car Model. Physics of Fluids, Volume 20(9), https://doi.org/10.1063/1.2952595

Roumeas M., Gilieron, P., Kuorta, A., 2009. Analysis and Control of Near Wake Flow over a Square Back Geometry. Computers \& Fluids, Volume 38(1), pp. 60-70

Roumeas M., Gilieron, P., Kuorta, A., 2009. Drag Reduction by Flow Separation Control on a Car after Body. International Journal for Numerical Method in Fluid, Volume 60(11), pp. $1222-1240$

Smith, B., Glezer, A., 1998. The Formation and Evolution of Synthetic Jets. Physics of Fluids, Volume 10(9), pp. 2281-2297

Smith, B.L., Swift, G.W., 2001. Synthetic Jets at Large Reynolds Number and Comparison to Continuous Jets. In: AIAA Computational Fluid Dynamics Conference

Uruba, V., 2009. On the Ahmed Body Wake. Issue Colloquium Fluid Dynamics, Institute of Thermomechanics AS CR, v.v.i., Prague

Utturkar, Y., 2002. Numerical Investigation of Synthetic Jet Flow Fields. Florida: Department of Mechanical Engineering, University of Florida 